\title{
Disability and Gender Based Violence: A Case of Couples with Children with Disabilities in Chainda, Lusaka
}

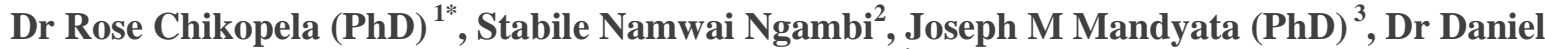 \\ Ndhlovu (PhD) ${ }^{4}$ \\ ${ }^{1}$ Zambia Institute of Special Education, Department of Hearing Impairment, Lusaka, Zambia \\ ${ }^{2}$ Department of Adult Education and Extension Studies, University of Zambia, Lusaka, Zambia \\ ${ }^{3}$ Department of Educational Psychology, Sociology and Special Education, University of Zambia, Lusaka, \\ Zambia \\ ${ }^{4}$ Institute of Distance Education, University of Zambia, Lusaka, Zambia
}

*Corresponding Author: Dr Rose Chikopela (PhD), Zambia Institute of Special Education, Department of Hearing Impairment, Lusaka, Zambia

\begin{abstract}
The purpose of the study was to explore the causes of Gender Based Violence (GBV) among parents with disabled children in Zambia. The main objective of the study was to establish whether or not having a child with a disability can lead to GBV. A case study design was used in this study and semi-structured interview guide was used to collect data from a sample of 20 parents in Chainda compound in Lusaka urban district of Zambia. Purposive sampling procedure was used to select the known parents who have children with disabilities. Snowball sampling procedure was used to trace other parents with children with disabilities. Focus group discussion guide and interview guides were used to collect data from parents. Interview and focused group discussions were conducted. Thematic analysis was used to analyse the data. The research discovered that having a child with a disability leads to GBV. The research revealed that the causes of GBV among parents with children with disabilities were; family disputes, ignorance, poverty, lack of employment, alcohol abuse, cultural beliefs, family background, blame game (where the couple blames each other for having such a child). The effects of GBV were separation, divorce, frigidity, impotence, infidelity, psychological disorder in the affected parent and the child, depression, physical injuries, children withdrawn from school, humiliation, intimidation and aggressiveness. The study also made some recommendations to curb GBV which were; the ministry of community development must be involved in Sensitization of the community on causes of disabilities, the government must provide employment opportunities to parents with children with disabilities and the ministry of home affairs must ensure that there is elimination of all forms of discrimination and stigmatisation against parents with children with disabilities in the community.
\end{abstract}

Keywords: disability, child, gender and violence.

\section{INTRODUCTION}

\subsection{Background}

Violence against women with disabilities shares common characteristics with violence against women with children with disabilities in general. Just like women with disabilities, women of children that have disabilities also experience various forms of abuse as a result of having such a child. Violence against women with disabilities and women to the disabled children is not just a subset of genderbased violence, - it is an intersectional category dealing with gender -based and disability-based violence. The confluence of these two factors results in an extremely high risk of violence against women that have disabled children (Hickman, (2000). Gender based violence is a problem affecting millions of couples globally and this manifests in various forms, for instance spouse battering among couples in the context of marriage or cohabitation (Benjamin \& Lynn, 2004). Dennis (2012) revealed that couples with children with disabilities face marital conflicts as a result of the children. Despite many efforts that have been put in place to fight GBV there is still GBV among couples all over the world.

According to Human Rights Watch, (2002), and the Convention on the Elimination of Discrimination Against Women (CEDAW) adopted in 1979 by the UN Assembly, discrimination against women is defined as 
“......any distinction, exclusion or restriction made on the basis of sex which has the effect or purpose of impacting or nullifying the recognition, enjoyment or exercise by women, irrespective of their marital status, on a basis of men and women, of human rights and fundamental freedom in the political, economic, social, cultural, civil or any other field."

By accepting the CEDAW's definition, states including Zambia, pledge themselves to undertake measures to end discrimination against women, precisely gender-based violence. On $29^{\text {th }}$ October, 2009 in Lusaka, former Zambian President, His Excellency, Mr. Rupiah Bwezani Banda, launched the National Communication Strategy against gender-based violence. The President called on all stakeholders to ensure that there was enough information through all media channels to empower the Zambian people to fully realize their rights and campaign against gender-based violence. He said gender-based violence was then the number two scourge in the country, next only to HIV and AIDS, in ravaging local society (NAP, 2008-2013).

The theme of the launch during the campaign was 'ABUSE, JUST STOP IT!" "HIV/AIDS has become the nation's number one enemy. Second is the sexual gender-based violence, and almost silent is the problem of human trafficking," said President Banda during the launch. As stated by former Republican President Mr. Rupiah Bwezani Banda almost ten years ago in 2009, this challenge is still rearing its head even today. He had said: "I, as the President of Zambia, state that the only action required is zero tolerance against gender-based violence. This whole situation creates an emergency in the case of Zambia as well as throughout Africa. I would like to reiterate that my government attaches great importance to creating conditions where women and children, and indeed men, live in harmony," (NAP, 2008-2013).

The National Action Plan on gender-based violence against Women and Children in Zambia (NAP, 2008-2013) further reported that:

Violence against women is a global health, human rights and development issue that transcend geography, class, culture, age, race and religion to touch every community in every corner of the globe. It has been estimated that at least one in every three women around has been beaten, coerced into sex or otherwise abused in her lifetime. The public health implications of this violence are enormous: according to a World Development report (2008), violence "is more serious a cause of death and incapacity among women of reproductive age as cancer and greater cause of ill-health than traffic accidents and malaria combined." It drains a country's resources and handicap women's ability to contribute to social economic progress (UNHCR, 2003).

The United Nation Declaration on the Elimination of Violence against Women makes the links between gender-based oppression and violence against women as "a manifestation of historically unequal power relations between men and women, which have led to the domination over and discrimination against women by men to the power of the full advancement of women." Wherever women are oppressed by their gender roles, children may be at an increased risk of violence. Article 19 of the Convention on the Rights of a Child (CRC) defines gender violence as injury and abuse, neglect or negligent treatment or exploitation, including sexual abuse. It also draws on the definition of violence in the 2002 World Report on Violence and health: the intentional use of physical force or power, threatened or actual, on a child, by an individual or group, which either results in or has high likelihood of resulting in actual or potential harm to a child's health, survival, development or dignity (RHCR, 2004).

The extent to which gender roles are used to both preserve and maintain women's subordinate status in relation to men has been identified as one of the most important underlying factors promoting violence against women. In fact, violence against women is often referred to as "gender-based violence."

The 2008 National Action Plan on Violence against Women and Children states that

The links between gender-based violence against women and increased risk of violence for girls are straightforward: girls, like their sisters, mothers, grandmothers, and aunts, are at direct risk of gender-based violence resulting from discrimination. In fact, a recent global analysis of violence against women conducted by the UN specifically identifies girls as one of 
the subgroups of females most prone to being targeted for violence because of the double vulnerability of gender and young age.

The report goes on to say that the link between gender-based violence against women and violence against boys is less direct, but no less significant. Whereas women and girls may be vulnerable to violence due to socially determined power differential between males and females that increases their risk of violence and limits their options to overcome or address it; boys may be victims of violence based on widely shared expectations of masculinity (UNCHR, 2003).

Surely anyone would agree that this continues to pose a great threat to our country's future as the numbers of victims are ever on the increase and the age of the targeted drastically reducing. The then Minister of Gender and Child Development, Inonge Wina, in the 2013 report, "No Violence Against Women", bemoaned the increase of gender based violence cases in the country despite putting in place comprehensive legal and policy framework aimed at reducing it. She also disclosed that according to a Victim Support Unit (VSU) report, cases of GBV were 10,217 in the year 2013 (NAP, 2008-2013). These alarming statistics just go to show us that the numbers need much consented effort from all stake holders in order for the fight to be curbed, and consequently reduced to zero.

\subsection{Purpose of the Study}

The purpose of the study was to establish whether or not having a child with a disability contributed to GBV among parents with children with disabilities in Zambia.

\subsection{Objectives of the Study}

The Following Objectives Guided this Study

- To establish whether or not having a child with a disability can lead to GBV among parents with children with disabilities

- To ascertain the effects attributed to gender based violence in the families that have a child with disability.

- To establish the effects attributed to gender-based violence among couples with children with disabilities.

\section{MeTHOdOLOGY}

\subsection{Research Design}

This was a qualitative study. McMillan and Schumacher (2001) define qualitative research as an inquiry in which researchers collect data in face-to-face situations by interacting with selected persons in their settings. A case study design was used. Sturman (1997) defines a case study as a "generic term for the investigation of an individual, group or phenomena", while Sternhouse (1985) defines a case study method as involving "collection and recording of data about a case or cases and the preparation of a report or the presentation of the case". A case study was used to gather information about the experiences that parents of children with disabilities go through, and how what they go through as a result of having a child with a disability leads to GBV.

\subsection{Population}

A study population has the total number of units from which data can potentially be collected (Babbie and Mouton, 2004). The population consisted of all parents with children with disabilities in Chainda compound of Lusaka.

\subsection{Sample}

Bless and Achola (1988) define a sample as the sub-set of the whole population which is actually investigated by a researcher and whose characteristics will be generalized to the entire population. The sample for this study comprised 20 parents of children with disabilities in Chainda compound of Lusaka urban district. This sample was chosen because the respondents met the requirements of the characteristics of the sample.

\subsection{Sampling Procedure}

Purposive sampling was used to select the known parents who have children with disabilities and snowball sampling procedure was used to trace other parents with children with disabilities. The power of purposive sampling lies in selecting information related to the central issues being studied (Kombo \& Tromp 2006). Here the investigator selects the particular units from the population from 
which relevant samples are drawn. In this study, all the known parents of children with disabilities were chosen to take part in the study.

\subsection{Instruments and Procedure for Data Collection}

Focus group discussion guide and interview guides were used to collect data from parents. McMillan and Schumacher (2006) explain that interviews are response questions to obtain data from participants about how they conceive and give meaning to their world and how they explain events in their lives. Borg and Gall (1989) advise researchers, especially novice researchers, to develop a guide to be used during the interview: "This guide makes it possible to obtain the data required to meet the specific objectives of the study." According to White (2005), an interview instrument "provides access to what is inside a person's head, makes it possible to measure what a person knows (knowledge or information), what a person likes or dislikes (values and preferences) and what a person thinks (attitudes and beliefs)". The focus group technique is a group interview research tool that is based on facilitating an organised discussion with a group of individuals selected because they are believed to be representative of some class. The interaction among focus group participants, in this case parents with children with disabilities, brought out different perspectives through the language that was used in an interactive setting. Parents drew each other out and sparked new ideas. The reactions of each parent sparked ideas in other parents and one parent may have filled in a gap left by other parents. As rightly put by White (2005), one may even find a form of collaborative mental work, as discussants build on each other to come to a consensus that no one individual would have articulated on their own.

\subsection{Data Analysis}

In this study, data was analysed using thematic and content analysis. Data was reduced to themes or categories. The focus group interviews were first transcribed to provide a complete record of the discussion. The researcher then analysed the content of the discussion by looking for trends and patterns that reappeared within a single focus group or among various focus groups. Similarly, data from interviews was categorised into common emerging themes as a way of understanding what was common in the lived experiences of parents with children with disabilities. Lungwangwa et al. (1995) confirm that the qualitative raw data from interviews, field notes on focused discussions and content analysis should be subjected to the constant comparative analysis technique in order to reach the most significant themes of the topic under study. White (2005) also observes that other considerations would be that which relate to consistency of comments and specificity of responses in follow up probes.

\section{FINDINGS AND DISCUSSION}

\subsection{Causes of GBV among Couples with Children with Disabilities}

Results indicate that ignorance on the causes of disabilities and family disputes were the major causes of GBV in families where they have children with disabilities. Table one provides details on the causes of GBV among couples.

Table1: Causes of GBV among couples with children with disabilities

\begin{tabular}{|l|l|l|}
\hline \multicolumn{1}{|c|}{ Causes of GBV } & \multicolumn{1}{c|}{ score } & \multicolumn{1}{c|}{$\%$} \\
\hline Family disputes & 4 & 20 \\
\hline Ignorance of causes of disabilities & 5 & 25 \\
\hline Poverty & 2 & 10 \\
\hline Lack of employment & 2 & 10 \\
\hline Alcohol abuse & 2 & 10 \\
\hline Traditional beliefs & 1 & 5 \\
\hline Spiritual beliefs & 2 & 10 \\
\hline Family background & 1 & 5 \\
\hline Blame game & 1 & 5 \\
\hline Total & 20 & 100 \\
\hline
\end{tabular}

The findings reviewed that family disputes between a couple lead to gender based violence. When there is disagreement on an issue between husband and wife either spouse could cause a fight. For example, a couple with a child with a disability might fail to agree on which school to take their child. A number of respondents alluded to the fact that some of their spouses would rather keep such children in their homes because they feel ashamed to take such a child to school. One parent said: 
Disability and Gender Based Violence: A Case of Couples with Children with Disabilities in Chainda, Lusaka

"I always quarrel with my spouse because he does not want our child to be exposed to the environment"

On the contrary, the other spouse would want such a child to be free and integrated with society. For this reason, such conflicts among couples with children with disabilities lead to gender based violence. As a result, family members on both sides also get involved and failure to resolve an issue causes the families to quarrel. This is in line with what Namiluko (2015) alluded to when she stated that at family level and relationships, cross cultural studies have cited male control of wealth and decision making within the family as strong causes of GBV.

The findings also revealed that Ignorance on causes of disability causes of GBV. Evidence has shown that a number of couples with children with disability do not know the causes of disability. This is due to the fact that some of these parents have linked disability of their children to witchcraft from the other spouse's family. This has brought unexplainable misunderstanding between the couples as well as their families at large. For example one of the parent (a man) said:

"Akaki bangu okamba kuti neyo kumuzi kwenechokera ndice afwiti chifukwa amalume banga be akwila ufiti kumuzi. Sopano akuti amalume ndiye eloza uyu mwana kuti abadwe olemala" (My wife says the village where I come from we are witches because my uncle was accused of practicing witchcraft. My uncle is the one who bewitched this child to be born with a disability).

In this study, blame game was among the causes of GBV. The study showed us that blame game was one of the major causes of GBV among couples with children with disabilities. There is clear evidence that blame game was either from the man or woman. For example, women were blamed for not going to ante-natal at the right time. For instance, one of the women in the study stated that:

"Ine lyonse abalume bandi balanda ati umwana wesu alilemana pantu na ambile ukuya ku chipimo pa myeshi itatu. Nshaishibe ati ndi nefumo." ("My husband always says that our child has a disability because I started going for ante-natal at 3 months. I never knew that I was pregnant").

Another woman said:

"My husband was having an extra marital affair during my pregnancy and this led to me having a child with a disability because I was always depressed".

Some people in the study also revealed that spiritual beliefs cause some couples to have a child with a disability because they were being punished by the gods for either their crimes they committed or those committed by their fore fathers. Similary, Kalabula (2007) in his study mentioned that some people who have blind children believe that they are being punished by the gods that is why they have such a child. One father said:

"In our village, when one has a child with a disability, it is believed that it is a punishment from the gods".

For this reason, a number of couples had failed to come to terms or accept that they have a child with a disability. This confirms Vujicic's (2010) explanation when he said that when he was born the pediatrician said as sensitively as possible to the mother "your son has neither arms nor legs." Afterwards, the medical staff offered to bring me to her but she refused to hold me and asked the medical personnel to take me away.

"Take him away," she said. "I don't want to touch him or see him." The research educates us on the fact that accepting to have a child with a disability is not automatic, For some it takes years but other couples have completely failed to come to terms with the situation and this has caused a lot of GBV especially were one of the spouses is leaving in denial and has failed to accept. Due to this factor, accepting to have a child with a disability is not automatic. It is a process that can take years. In some marriages others have failed to accept that they have such a child. In contrast, Harland's (2002) study revealed that some families with disabled children are able to find the strength within themselves and among their circles of support to adapt and handle the stress and challenges that may accompany their child's illness or disability.

A number of respondents claimed that lack of employment which leads to live in poverty stricken condition caused GBV among couples with children with disabilities. They explained that having a child with a disability is costly due to special medication required for them to live a healthy life and 
School fees which are high because most of them go to special schools whilst some of the schools are not in their locality hence use public transport to ferry them while other children are taught from homes because of distance to the special school. For example, one father said:

"It is very expensive to meet the needs of this child e.g, school fees and medication among others but when I explain to my wife that I cannot afford to meet all the costs she does not understand as a result we quarrel and fight"

This shows that failure to meet these needs by mostly the father causes quarrels and eventually fights. The fact that many couples or families with special children in Chainda compound live in poverty due to lack of employment led to stress among parents which resulted in GBV. For example, failure to pay school fees and medical fees caused havoc in homes because tempers were rising especially among men. Similarly, Dennis (2012) in his study mentioned that, insufficient income from the father to meet the needs of the child leads to marital conflicts as a result most couples become victims of GBV and this situation leads to either separation or divorce. In addition, Mtonga, et.al., (2015) also discovered in their research that lack of employment caused poverty and poverty led most men and some women resorting to drinking everyday hence caused GBV. Women in this case are left without food while men are not respected by their women and a home is neglected.

The findings also revealed that traditional beliefs are among the factors that cause GBV. In most cultures in Zambia, it is believed that when a man has an extra marital affair when his wife is pregnant it may lead to having a child with a disability as well as death of the mother during child birth. For example, one of the women said:

"My husband was having a sexual affair when I was pregnant, that caused me to have this child with a disability"

It was revealed that many women accused their men of having extra marital affairs during their pregnancy which led to having a child with a disability. Due to this factor, such accusations have led to a number of conflicts that lead to wife battering as well as a feeling of condemnation and depression in some men.

\subsection{Effects Attributed to Gender Based Violence in a Family that has a Child with a Disability}

The study revealed numerous effects attributed to GBV in the families that have children with disabilities. These effects were seen on children, dependants and couples.

This study found that children who are disabled and know that their parents are having disputes because of them turn to become depressed and attempt suicide. Some parents of these children confirmed that once their children discovered that their parents are arguing or fighting because of their condition they become sad, depressed and others never wished they exist on earth and attempted to eliminate their lives. For this reason, children in this situation tend to blame themselves for causing such fights.

GBV reduces self esteem of children in an affected family. Children with disabilities as well as their non disabled siblings tend to have low self esteem. The findings discovered that children from homes where they have a disabled sibling have low self esteem if their parents are involved in GBV and this even affects their performance at school. One parent said:

"Whenever we quarrel in the presence of our daughter, she stops talking to everyone at home and refuses to go to school".

Similarly, Heise et al., (1991) found collateral effects on children who witness violence at home such as emotional and behavior disturbances which can be exhibited in withdrawal and aggressiveness. This is also manifested in low performance at school. This shows evidence that GBV between parents has devastating effects on children with disabilities.

Research findings discovered that GBV among parents with children with disabilities leads to divorce. This is in line with the findings of Heise et al., (1999) who contend that gender violence threatened family structures. Direct effects include divorce or broken family, jeopardized family's economic and emotional development. This finding seems to suggest that having a child with a disability also adds to the increasing number of divorces in Zambia.

Apart from divorce, the research revealed that a good number of couples with children with disabilities involved in GBV had been on separation before while others were on separation. This could be interpreted to imply that couples encounter too many fights as a result resort to separating from one another due to having a child with a disability. One of the parents said: 
"My wife and I have been on separation for two months because we fighting a lot. I still do not understand how she gave birth to such a disabled child."

Depression is one of the effects of GBV according to our research findings. This concretises Brinegar's (1992) statement that effects can be direct or indirect. Direct effects include; inability to concentrate, loneliness, post-traumatic stress disorder, depression and suicide. Some parents may also feel humiliated and intimidated because of having a child with a disability. Taken together, these results indicated that parents with children with disabilities went through a lot of psychological and emotional problems.

Infidelity was another finding on the effects attributed to GBV among couples with children with disabilities. One of the respondents (male) stated that:

"My wife started having extra marital affairs because we have a child with a disability"

Infidelity has led to HIV/AIDS infections among couples and even deaths.

The research also revealed that GBV among couples with children with disability caused frigidity in women and impotence in men. For this reason, there is a lot of mistrust on couples that undergo this situation.

Physical injury was also identified as one of the effects attributed to GBV. This is due to the fact that some people have been left with injuries on their bodies after being victims of GBV.

\section{CONCLUSION AND RECOMMENDATIONS}

Based on the findings of the study, it is concluded that having children with disabilities contributes to Gender Based Violence among parents. The study therefore recommends that; (i) Ministry of community development must be involved in Sensitization of the community on causes of disabilities.

(ii) The government must provide employment opportunities to parents with children with disabilities.

(iii) The ministry of home affairs must ensure that there is elimination of all forms of discrimination and stigmatisation against parents with children with disabilities in the community.

\section{REFERENCES}

[1] Adrienne C. and Sabine K. (2011). Gender-Based Violence in the world of work: Overview and selected annotated bibliography. New York: International Labour Office.

[2] Babbie, E \& Mouton, J. 2004. The practice of social research, Oxford: Oxford University Press.

[3] Borg, W.R. \& Gall, M.D. 1989. Educational Research, An Introduction, 5th Ed. London: Longman Group Ltd.

[4] Benjamin, J. B and Lynn, M. (2004). Gender-Based Violence: Care \& Protection of Children in Emergencies. A Field Guide, Save the Children Federation Inc.

[5] Bless, C. \& Achola, P. 1988. Fundamentals of Social Research Methods: An African Perspective, Lusaka: Government Printer.

[6] Dennis H. (2012). Family consequences of children's disability. Russell Sage Foundation: New York.

[7] Kalabula, M. D. (2007). Special Education in Zambia. Lusaka. Lusaka: Musumali Press.

[8] UNDP (2012). Strengthening the role of adjudicators in handling Gender Based Violence. Lusaka: UNDP.

[9] Southern Africa HIV and AIDS Information and Disermination Services (SAFAIDS) (2014) Baseline Survey: Gender Based Violence

[10] Hickman, L. (2000). Living in my skin: The insider's view of life with a special needs child (p. 246). San Antonio, TX: Communication Skill Builders.

[11] McMillan, J.H. \& Schumacher, S. 2001. Research in education: A conceptual introduction. 5th ed. New York: Longman.

[12] Namiluko L. (2015). The causes and effects of gender Based Violence against women of Chawama compound in Lusaka. Unpublished report; unza; Lusaka.

[13] National Action on Gender Based Violence (NAP-GBV) 2008-2013.

[14] Vujicic, N. (2010). Life without limbs. New York: Grown Publishing Group.

[15] Harland's (2002) Harland, K. (2002). A will of his own: Reflections on parenting a child with autism (p. 33). Bethesda, MD: Woodbine House.

[16] Human Rights Watch (2002). Suffering in Silence: The links between abuses and HIV transmission to Girls in Zambia p53-54.

[17] McMillan, J.H. \& Schumacher, S. 2006. Research in education: Evidence-Based Inquiry, London: Pearson Education, Inc. 
[18] Mtonga, M., Muzyamba, M., and Hachibe , A. (2015). An investigation of factors leading to the increase of Gender Based Violence in Mandevu Township. Unpublished report: unza; Lusaka,

[19] Heise, E. L. and Gottemoeller. R. (1991). Ending Violence against Women. Population Reports Series (11). Baltimore: John Hopkins University.

[20] Kombo, D. K. \& Tromp, D. L. A. 2006. Proposal and thesis writing: An Introduction, Nairobi: Pauline publications Africa.

[21] Sternhouse, L. 1985. Case study methods. In Husen, T and Postlethwaite, N.T. (Ed.) The International Encyclopedia of Education, 645-650, Oxford: Oxford: Pergamon Press.

[22] Sturman, A. 1997. Case study methods. In J.P. Keeves (Ed.) Educational Research Methodology and Measurement: An International Handbook, pp. 173-179, Oxford: Pergamon Press.

\section{AUTHORS' BIOGRAPHY}

Dr. Rose Chikopela is a senior lecturer at the Zambia Institute of Special Education and a part-time lecturer in the School of Education, Department of Educational Psychology, Sociology and Special Education at the University of Zambia. She holds a doctoral degree in Special Education, Masters Degree in Special Education and Bachelor's Degree in Special Education from the University of Zambia. Rose has vast experience in teaching and lecturing at all the levels of education. She has done numerous research activities and publications in local and international refereed journals. Rose has also participated in various national and international education conferences.

Stabile Namwai Ngambi is a lecture at the University of Zambia in the school of Education, Department of Adult Education and Extension Studies. At departmental level she is the conferences and workshops Co-Ordinator. she conducts research in Zambia and has also done collaborative research at international level. Stabile has presented papers in local and international conferences. she has published book chapters and articles. Her areas of research interest are; Guidance and Counselling, Extension Education, Lifelong Learning and education, rurality and education as well as participatory approaches to development and training of trainers.

Dr. Joseph Mwape Mandyata is currently a university lecturer and researcher in special and Inclusive Education in the School of Education, Department of Educational Psychology, Sociology and Special Education at the University of Zambia. He has served in various academic and education positions such as: external and internal examiner of students at postgraduate level, Assistant Dean in the School of Education; Senior Inspector of Schools (special education); a senior Education Standards Officer (special Education); District Inspector of schools, Head Teacher of special education school, special education teacher and as a Secondary School teacher in the Zambian Ministry of Education. He has researched and published several articles in the field of special and inclusive education in local and international journals. He holds a Doctor of Philosophy Degree in Special Education, Master of Education in Special Education and a Bachelor of Arts with Education Degree of the University of Zambia. He lectures in Special Education and guidance and counselling courses at both postgraduate and undergraduate degree programmes. His research interests are: Policies in Special / Inclusive Education; Partnerships in Special / Inclusive Education; Guidance and Counseling, Disability, Education and Poverty for persons with disabilities.

Dr. Daniel Ndhlovu is a Senior lecturer in the Department of Educational Psychology, Sociology and Special Education at the University of Zambia. He holds a doctoral degree in Special Education, Masters Degree in Education and Bachelor's Degree in Special Education from the University of Zambia. In addition to lecturing, he has held senior administrative positions at the University of Zambia which includes Assistant Dean Postgraduate in the School of Education and Assistant Director Postgraduate in the Institute of Distance Education. Daniel has 31 years teaching and lecturing experience at secondary school, tertiary and university levels of education. He has undertaken numerous research activities and publications in local and international refereed journals.

Citation: Dr Rose Chikopela, Stabile Namwai Ngambi, et.al. "Disability and Gender Based Violence: A Case of Couples with Children with Disabilities in Chainda, Lusaka". International Journal of Humanities Social Sciences and Education (IJHSSE), vol. 6, no.9, 2019, pp. 22-29. doi: http://dx.doi.org/10.20431/2349. 0381.0609003 .

Copyright: (C) 2019 Authors. This is an open-access article distributed under the terms of the Creative Commons Attribution License, which permits unrestricted use, distribution, and reproduction in any medium, provided the original author and source are credited. 